\title{
ONTOLOGÍAS DEL SER SOCIAL (LUKÁCS, GOULD, NEGRI, HARDT, BALIBAR)
}

\author{
Daniel Alvaro \\ Universidad de Buenos Aires/CONICET - IIGG ${ }^{1}$
}

http://dx.doi.org/10.5209/rev_NOMA.2015.v45.n1.51328

\begin{abstract}
Resumen: Sin programa ni proyecto, sin mayores indicaciones ni definiciones claras en esa dirección, hay una ontología en Marx. Dicha hipótesis no es original ni mucho menos. Con todo, es significativo que a lo largo de la rica historia interpretativa que desde hace un siglo y medio se despliega en torno a Marx, la cuestión ontológica ocupe un lugar tan reducido y sin duda marginal. Para ello hay razones más o menos evidentes y otras que no lo son tanto.

El presente trabajo se propone realizar una lectura atenta de aquellos textos que habrían llevado más lejos el análisis de la ontología marxiana del "ser social". Se trata fundamentalmente de textos de autores conocidos del marxismo occidental: Georg Lukács, Carol Gould, Antonio Negri, Michael Hardt y Étienne Balibar. Aunque a medida que se avance en esta lectura habrá que dar lugar a nuevos textos y a nuevos autores que, acaso menos directamente que los anteriores, también habrían contribuido al análisis de la cuestión ontológica en Marx.
\end{abstract}

Palabras clave: ontología, ser social, Marx,relación, trabajo, producción

\begin{abstract}
Without program or project, with no major indications or clear definitions in that direction, there is an ontology in Marx. This hypothesis is not original or what so ever. With that been said, it is significant that along the rich interpretative history that since a century and a half has been displayed around Marx, the ontological question occupies such a reduced and, undoubtedly, marginal place. For that, there are reasons that are more or less evident, and others that are not much so.

The present work aims to realize an attentive reading from those texts that would have carried farther the analysis of the marxian ontology of the "social being". It fundamentally addresses the texts of known authors from the occidental marxism: Georg Lukács, Carol Gould, Antonio Negri, Michael Hardt y Étienne Balibar. Though, as the reading advances, it will have to give place to new texts and authors that, perhaps less directly than the previous ones, would also have contributed to the analysis of the ontological question in Marx.
\end{abstract}

Key Words: ontology, social being, Marx,relation, labour, production

Desde hace al menos dos décadas asistimos a un movimiento del pensamiento de importancia y visibilidad crecientes en el mundo académico. En un gran número de disciplinas pertenecientes a diversas áreas del conocimiento se puede constatar lo

\footnotetext{
${ }^{1}$ Daniel Alvaro es Doctor en Ciencias Sociales por la Universidad de Buenos Aires (UBA) y Doctor en Filosofía por la Université Paris 8 Vincennes - Saint-Denis. Es investigador del Consejo Nacional de Investigaciones Científicas y Técnicas (CONICET) con sede en el Instituto de Investigaciones Gino Germani de la UBA, y es docente de la materia "Teoría Estética y Teoría Política", perteneciente a la carrera de Sociología de la misma universidad. Asimismo, desarrolla actividades docentes y dicta seminarios de doctorado en distintas universidades argentinas. Ha publicado artículos y ensayos en revistas nacionales y extranjeras, y ha traducido obras de Jacques Derrida y Jean-Luc Nancy. Es coordinador y coautor de Jean-Luc Nancy: arte, filosofía, política (Buenos Aires, Prometeo, 2012) y autor de El problema de la comunidad. Marx, Tönnies, Weber de próxima aparición en la editorial Prometeo.
} 
que se ha dado en llamar un "giro ontológico". ${ }^{2}$ Dicho giro implica tanto un viraje hacia la ontología, es decir, un renovado interés por este saber filosófico, como también un viraje de o en laontología, es decir, un cambio, muchas veces radical, en el modo mismo de teorizarlo y practicarlo. Huelga decir que este movimiento adopta diferentes modalidades al interior de cada una de las disciplinas donde opera. Lo que está en juego es nada menos que una evaluación general, multidisciplinar y multiperspectivista, sobre los alcances y posibilidades actuales del saber que se ocupa de todo aquello que "es".

Aquí no es cuestión de tomar partido a favor o en contra del mentado giro ontológico. Sólo quisiera destacar uno de sus efectos más significativos. Hablo de la posibilidad de examinar o reexaminar el enfoque ontológico y las obras de algunos de sus mayores representantes de todas las épocas con menos aprensiones que las habituales cuando se trata de esta cuestión. Hasta el día de hoy pesa sobre la ontología una desconfianza generalizada por su identificación simple y llana con la metafísica. La "ontología" y la "metafísica" son nombres emparentados con la "filosofía", utilizados tradicionalmente y de manera general para designar el conocimiento teórico que trata del ser. En la Metafísica, Aristóteles define la filosofía como "la ciencia que estudia el ente en cuanto ente y las determinaciones que por sí le pertenecen"; y agrega de inmediato que ella "no se identifica con ninguna de las llamadas ciencias particulares, pues ninguna de éstas considera en su universalidad al ente en cuento ente, sino que, después de haber deslindado alguna porción de él, estudia lo que le pertenece accidentalmente por sí a esa cosa" (2004, 1003a, 20-25). La ciencia que estudia el ente en cuanto tal, y que por lo tanto es la más universal y abarcadora, recibe de Aristóteles el nombre de "filosofía primera". La filosofía así entendida es una ciencia eminentemente teorética. No trata de los entes particulares, ni siquiera de un determinado tipo de entes, sino de los entes en general.

A diferencia de lo que sucede con el término "metafísica", que tiene su origen en la antigüedad, $^{3}$ el término "ontología" nace en tiempos modernos. Si bien se lo usa por primera vez en el siglo XVII, es recién en el siglo XVIII cuando adquiere su significado más corriente. Desde entonces, la ontología es el saber que se ocupa de los entes, vale decir, de todo lo que "es", mientras que la metafísica, en sentido amplio, busca el fundamento del ente. Puesto que la metafísica conoció versiones

\footnotetext{
${ }^{2}$ La expresión "giro ontológico", tal como la uso aquí, no remite a un autor particular ni refiere a una teoría específica, aun cuando son muchos los autores y las teorías que hoy se sirven de ella. Uso la expresión en sentido laxo para designar una inquietud, y hasta cierto punto una tendencia, que de forma heterogénea atraviesa tanto a la filosofía y a las ciencias sociales como a las ciencias formales y naturales.

${ }^{3}$ Los escritos aristotélicos dedicados a estudiar los primeros principios y las primeras causas hoy conocidos como Metafísica fueron reunidos en el siglo I a.C. por Andrónico de Rodas, responsable tanto del título del libro como de su organización actual. El título tiene en principio un sentido clasificatorio, puesto que al momento de ordenar la obra de Aristóteles dichos escritos fueron ubicados "más allá" o "detrás" (metà) de los de la Física. Sin embargo, a este primer sentido se agrega otro acaso menos técnico, en la medida en que la "filosofía primera" puede y suele interpretarse como el estudio de lo que está "más allá" o "detrás" de la "física" (physiká), es decir, de la "naturaleza" (phýsis).
} 
muy diferentes a lo largo de la historia, sumado al hecho de que hasta el día de hoy no existe acuerdo acerca de cuál es su "objeto" de estudio ni de si tiene uno, resulta difícil, si no imposible, ofrecer una definición satisfactoria de la misma. Sin embargo, se puede decir, siempre en líneas generales, que la metafísica constituye una tentativa por elucidar problemas trans-físicos, sea el primer motor inmóvil, la existencia de Dios, o la noción de alma, por sólo citar algunos ejemplos célebres.

Ahora bien, en la actualidad, tanto los análisis que toman en cuenta la ontología como aquellos que asumen abiertamente una perspectiva ontológica son, en su inmensa mayoría, críticos de la metafísica. Justamente, lo que empieza a ser evidente gracias a este vuelco hacia y de la ontología, es que la pregunta por el ser no implica necesariamente complicidad con las determinaciones metafísicas del ser. Ciertas ontologías viejas y nuevas contribuyen directa o indirectamente al cuestionamiento de la metafísica occidental allí donde esta detenta la especulación y el dogmatismo, el punto de vista teológico, la posición trascendental, el sustancialismo, etc.

En efecto, hay que tener en cuenta que algunos de los proyectos ontológicos más importantes de este siglo y del anterior, comenzando por la "ontología fundamental" de Martin Heidegger, se proponen manifiestamente una embestida contra la metafísica o, más precisamente, su destrucción. Aún antes de que diversas corrientes de la filosofía contemporánea influenciadas principalmente por Nietzsche asumieran la tarea de desandar críticamente la tradición metafísica, se puede dar cuenta de ontologías radicales que desafiaron esta tradición en algunos de sus presupuestos más elementales. Cuando pensamos en ello, los primeros nombres que suelen asomar, por la radicalidad de sus pensamientos y por la indiscutible incidencia de sus obras en el presente, son los de Spinoza y Marx. Que hay una ontología spinozista y que esta se encuentra en el centro de algunos de los debates académicos y políticos más interesantes de nuestro tiempo es un hecho que no necesita confirmación. Sin embargo, lo mismo no puede decirse de la ontología marxiana. Incluso, dirán algunos, habría que empezar por preguntarse si existe tal cosa, si es posible hablar en estos términos sin falsear por un lado el sentido de lo que llamamos ontología y, por otro lado, al propio Marx y su legado. Creo que la pregunta es legítima puesto que a diferencia de lo que sucede con Spinoza - para seguir con él-, en Marx no hay, no explícitamente al menos, un proyecto o un programa ontológico, lo cual no quiere decir que su obra carezca de potencia en ese sentido.

Con este breve rodeo introductorio no hago más que contextualizar mínimamente la exposición y comenzar a apuntalar una hipótesis de lectura. Pues aun sin programa ni proyecto, sin mayores indicaciones ni definiciones claras en esa dirección, hay una ontología en Marx, una ontología marxiana. Dicha hipótesis no es original ni mucho menos. Con todo, es significativo que a lo largo de la rica historia interpretativa que desde hace un siglo y medio se despliega en torno a Marx, la cuestión ontológica ocupe un lugar tan reducido y sin duda marginal. Para ello hay razones más o menos evidentes y otras que no lo son tanto. A su tiempo hablaré de unas y otras. Los autores que a lo largo de esta historia hicieron 
consideraciones de este orden son ciertamente poco numerosos. Todos ellos son nombres conocidos del marxismo occidental: Georg Lukács, Carol Gould, Antonio Negri, Michael Hardt y Étienne Balibar entre algunos otros.

Como es de esperar, sus interpretaciones difieren entre sí. Lo que interesa aquí son las variaciones entre una lectura y otra, entre lo que cada uno elige leer y dar a leer sobre la ontología de Marx. Pero más allá de las diferencias - pequeñas, grandes o insalvables según los casos- todos ellos se encuentran confrontados a la figura marxiana del "ser social". A partir de Marx, y por intermedio suyo, esta figura se ha vuelto frecuente en los discursos de las llamadas humanidades. Su contexto de emergencia es aquel de los encendidos debates entre los seguidores más radicalizados de Hegel. Pero es Marx, por decirlo así, quien la puso en circulación. Desde entonces y hasta la actualidad, con mayor o menor constancia según las coyunturas y las modas académicas, nunca dejó de circular. La cuestión del "ser social", del "ser común" o "comunitario", incluidas sus variantes o declinaciones, es aquella donde confluyen dos tradiciones de pensamiento que parecen destinadas a sobrepujarse interminablemente: la ontología o ciencia del ser, por una parte, y las ciencias sociales o humanas, por otra. Esta confluencia, que no es una resolución dialéctica entre contrarios, sino más bien la articulación de dos dimensiones de análisis mutuamente implicadas, permite pensar lo que se ha dado en llamar una ontología social o también una ontología de lo común. ${ }^{4}$

El presente trabajo se propone realizar una lectura atenta de aquellos textos que habrían llevado más lejos el estudio de la ontología de Marx. Se trata, fundamentalmente, de textos de los autores mencionados más arriba: Lukács, Gould, Negri, Hardt y Balibar. Aunque a medida que se avance en esta lectura habrá que dar lugar a nuevos textos y a nuevos autores que, acaso menos directamente que los anteriores, también habrían contribuido al análisis de la cuestión ontológica en Marx.

En suma, lo que se pretende es empezar a poner en evidencia, por poco que sea, hasta qué punto la historia pasada, presente y futura de las disciplinas asociadas al inmenso campo de las humanidades - si se trata efectivamente de un campo y si este nombre cada vez más insostenible de "humanidades" todavía es capaz de representarlo- se encuentra atravesada por esta decisiva cuestión hasta ahora marginalizada o sencillamente ignorada.

\section{Lukács}

$\mathrm{Ni}$ antes ni después de Lukács es posible encontrar otro pensador que se haya dedicado como él lo hizo a la investigación de la ontología marxiana. Fuera del círculo de los especialistas es un hecho más bien poco conocido que la última obra de envergadura de Lukács, publicada póstumamente, es un libro de

\footnotetext{
${ }^{4}$ Sobre este tema y a modo de introducción para todo lo que sigue, remito a mi artículo (Alvaro, 2012).
} 
extensión considerable al que dedicó los últimos años de su vida y que lleva por título Ontología del ser social (Lukács, 1984, 1986). ${ }^{5}$ El manuscrito de este libro, escrito entre 1964 y 1971 (año de la muerte del autor), forma parte de un proyecto filosófico de más vasto alcance. Hacia 1960, una vez finalizada la Estética, Lukács decidió escribir una Ética. Esta última nunca vio la luz pero fue precisamente durante los trabajos preparatorios a la misma que se dispuso a escribir una Ontología como paso previo y a su vez introductorio a la proyectada Ética. ${ }^{6}$

El primer escrito donde aborda sin rodeos la pregunta por la ontología de Marx se titula "Los fundamentos ontológicos del pensamiento y de la acción humanos" (Lukács, 1984; Lukács, 2004). ${ }^{7}$ Allí se propone "señalar lo que fue filosóficamente decisivo en la actividad de Marx: trazar el esbozo de una ontología materialista histórica, superando, tanto teórica como prácticamente, el idealismo lógicoontológico de Hegel" (2004, p. 36). En una fórmula breve se revela una tarea inmensa. A la dificultad analítica que supone un trabajo semejante, se agrega una dificultad de otro orden que Lukács pone de manifiesto desde el comienzo mismo del texto, a saber, que "el marxismo", "en las historias de la filosofía, rara vez ha sido considerado como una ontología" (2004, p. 36). Si aún hoy se encuentra resistencia en ese sentido, no es difícil imaginar lo que sucedía a fines de los años '60. Como ya se ha dicho, no es que por entonces faltaran programas ontológicos, sino más bien que ninguno de ellos parecía dispuesto a reconocer en la obra de Marx una indagación sobre el ser, salvo por algunas notables excepciones. ${ }^{8}$

Dicho esto tampoco puede sorprender la escaza recepción que tuvo la aparición de la Ontología, de la que se editaron fragmentos y traducciones desde 1971, pero

\footnotetext{
${ }^{5}$ La misma se encuentra parcialmente traducida al castellano: Marx, ontología del ser social (2007) reproduce el capítulo IV, "Marx, Ontologie" de Zur Ontologie des gesellschaftlichen Seins (Darmstadt und Neuwied, Luchterhand, 1972), una primera edición parcial de la obra en alemán; Ontología del ser social: El trabajo (2004) reproduce el capítulo I, "Die Arbeit" de la Segunda Parte de la edición integral, además de otros textos inéditos de Lukács en castellano; y Ontología del ser social: La alienación (2013) reproduce el capítulo IV, "Die Entfremdung", de la Segunda Parte de la edición integral.

6 Para una historia ampliada de la redacción y publicación de la Ontología, véase (Infranca y Vedda, 2004).

${ }^{7}$ Según informan los editores de la versión castellana, el texto fue concebido originalmente como una conferencia para el XIV Congreso Internacional de Filosofía que tuvo lugar en Viena en 1968 pero donde finalmente no fue expuesto.

${ }^{8}$ De maneras muy diferentes, M. Heidegger y N. Hartmann, responsables de dos de los programas ontológicos más ambiciosos del siglo XX, influenciaron a Lukács. Con la filosofía de Heidegger y, en general, con lo que a lo largo de la Ontología se entiende por "existencialismo", Lukács tiene severas reservas. Respecto de la "ontología crítica" de Hartmann, por el contrario, tiene una opinión muy favorable y hasta cierto punto se podría decir que en el plano estrictamente teórico existe una suerte de continuidad entre ambos pensadores. Con todo, Hartmann permaneció más o menos indiferente a la obra de Marx. Probablemente, el único autor de la órbita marxista antes de Lukács en desplegar un proyecto ontológico fue J.-P. Sartre, cuyo libro Crítica de la razón dialéctica (1960) es discutido y criticado en la Ontología. Asimismo, cabe señalar que pocos años después de la muerte de Lukács, pero antes de la edición definitiva de su Ontología, aparecieron los libros de M. Henry, Marx (1976), de C. Gould, Marx's Social Ontology (1978), y de G. Haarscher, L'ontologie de Marx (1980), donde se analizan desde perspectivas diferentes los conceptos ontológicos del pensamiento marxiano.
} 
cuya primera edición integral en alemán —lengua en la que fue concebida - se publicó en dos volúmenes, el primero en 1984 y el segundo en 1986. Además del hecho de que los filósofos contemporáneos, independientemente de su posición ideológica, rara vez habían considerado al marxismo como una ontología, la fría recepción de esta obra se puede explicar por otros motivos. Ni la coyuntura política, signada por el precipitado derrumbe de los socialismos en el mundo, ni el clima filosófico del momento, marcado por el auge de una gran variedad de teorías de distinto signo que cuestionaban fuertemente la ontología, eran las más propicias para dar cabida a una obra como esta. A decir verdad, ni los propios discípulos de la "Escuela de Budapest" aprobaron este último y monumental escrito con el que paradójicamente Lukács creía haber dado, según el testimonio de Nicolas Tertulian, "una expresión definitiva y esencial a su pensamiento" (2011, p. 10).

Resulta evidente, pues, que la Ontología es un texto escrito y publicado a destiempo y a contramano. No obstante, es sintomático que hoy, a tres décadas de su primera edición integral en alemán durante las cuales pasó prácticamente inadvertido, sea editado o reeditado simultáneamente en diferentes países del mundo. Este hecho no parece ser ajeno ni al fenómeno del "giro ontológico", ni, sobre todo, al interés reciente por la ontología de Marx.

Para empezar debe quedar claro que el proyecto de Lukács es un intento verdaderamente osado por renovar la ontología marxiana al mismo tiempo que una tentativa de formular una nueva ontología. Lo segundo a través de lo primero. Lukács no sólo se posiciona como comentarista, lector o intérprete de la ontología de Marx, sino como alguien que a partir de Marx se propone construir un nuevo sistema ontológico. Esta apuesta ya se pone de manifiesto en la conferencia de 1968, "Los fundamentos ontológicos del pensamiento y de la acción humanos", suerte de introducción y resumen de la Ontología. Allí, como se decía más arriba, Lukács define lo decisivo de la filosofía de Marx como una ontología materialista que supera, en la teoría y en la práctica, a la ontología idealista de Hegel. "En Marx, el punto de partida no es el átomo, como en los viejos materialistas, ni el ser abstracto, como en Hegel. Todo lo existente debe poseer siempre carácter objetivo, debe ser siempre la parte más motora y móvil de un complejo concreto" (2004, p. 36).

El punto de partida de la ontología materialista así entendido supone una radicalidad sin precedentes. Marx se aparta tanto de los antiguos materialistas, quienes partían del átomo indivisible -y a los que por otra parte, recordémoslo de paso, había dedicado su tesis doctoral (Marx, 1982)—, como de Hegel, quien a pesar de haber historizado la ontología, partía sin embargo de un ser ideal y abstracto. Para Lukács, el hecho de que Marx haya tomado como punto de partida la existencia objetiva constituye en sí mismo un hecho revolucionario y de la máxima importancia tanto para la renovación del marxismo (caído en descrédito, según su opinión, por efecto de la vulgata ortodoxa propagada durante el estalinismo) como para la renovación de la filosofía y las ciencias en general (amenazadas por el avance arrollador del pensamiento neopositivista). 
Como intento mostrar en este trabajo, la radicalidad de la posición ontológica de Marx se puede explicar de muchas maneras. La explicación de Lukács empieza por levantar acta de dos cuestiones que estarán presentes a lo largo de toda su Ontología. La primera consecuencia que saca del punto de partida de Marx es que "el entero ser (das gesamte Sein) es un proceso histórico". Esto quiere decir que el ser no mantiene una relación de interioridad ni de exterioridad respecto a la historia, sino que es, él mismo, un desarrollo histórico. Contrariamente al ser eterno, inmóvil y separado de la materia propio de la metafísica tradicional, aquí el ser en su totalidad es móvil y material. Lo que Lukács entiende por complejo (Komplex) es un conjunto de elementos diversos que puede ser de naturaleza inorgánica, orgánica y social. Volveré sobre este punto.

La segunda consecuencia refiere al estatuto de las categorías del pensamiento. Al afirmar que las categorías o los conceptos no son enunciados ni principios formales sobre la materia, sino formas de la materia o incluso, según el enunciado de Marx citado en el texto, "formas del ser, determinaciones de la existencia" (Daseinsformen, Existenzbestimmungen), Lukács aspira a dilucidar dos puntos controvertidos. Por un lado, busca refutar la idea, muy extendida en cierto marxismo de la época, según la cual los productos de la conciencia serían menos importantes que el ser material. Según Lukács, el hecho de que Marx haya concebido la conciencia como un "producto tardío" del desarrollo ontológico, no vuelve a la conciencia menos decisiva desde la perspectiva relativa al ser. Por otro lado, y en la misma dirección, busca afirmar el "poder concreto" de la ontología como un modo de reivindicar este saber al que siempre se tuvo por demasiado abstracto, razón por la cual habría sido rechazado por buena parte de los autores marxistas de todos los tiempos.

En la conferencia de 1968, al igual que en la Ontología, se trata ante todo de determinar la especificidad del ser social. Para ello Lukács va a analizar paso a paso aquellas instancias que hicieron posible su surgimiento y desarrollo. El ser social surge del ser orgánico, y este surge a su vez del ser inorgánico (2004, p. 37 y ss.). Entre las distintas formas del ser existen múltiples transiciones y gradaciones. La forma correspondiente al ser social es "algo cualitativamente nuevo", algo esencialmente distinto de las formas que la preceden en el desarrollo "ascendente" del ser. Entre aquella y estas existe una diferencia cualitativa o, más precisamente, como se lee en la Ontología, un "salto ontológico" (ontologische Sprung). Dicho salto debe entenderse como una transformación del ser al interior de un proceso dialéctico. Es decir que el ser social no se independiza del ser orgánico y del ser inorgánico, sino que los presupone. El ser social comporta un cierto grado de desarrollo de la naturaleza orgánica, mínimamente, el grado de desarrollo necesario para que se forme la conciencia en el viviente humano.

La conciencia opera como demarcación entre el ser orgánico y el ser social. Dicho de otra forma, la conciencia es el resorte del salto ontológico, al que Lukács identifica propiamente con el trabajo. He aquí la categoría central de la ontología lukácsiana. El trabajo es definido como "fundamento dinámico-constructivo de una nueva clase de ser", que es el ser social. Y "[l]a esencia del trabajo consiste, justamente, en la capacidad de rebasar la fijación del ser viviente en la relación 
biológica con su ambiente" (2004, p. 38). Desde el momento en que el ser viviente es capaz de satisfacer una necesidad determinada a través de una actividad conscientemente dirigida, esto es, desde el momento en que el "animal", mediante el trabajo, se convierte en "hombre", se puede hablar con toda propiedad de ser social, de vida social. El surgimiento del ser social es indisociable de la hominización del hombre. El trabajo consuma el salto de la "naturaleza" (inorgánica y orgánica) a la "sociedad". Su peculiaridad ontológica consiste en relacionar estos distintos niveles del ser. Al igual que Hegel, Marx y tantos otros pensadores que lo precedieron, Lukács entiende el trabajo como un proceso teleológico, es decir, como un proceso impulsado por la conciencia que conduce la actividad en determinada dirección y con un fin preciso.

Ahora bien, para hacerse una idea del privilegio que ostenta la categoría de trabajo en la ontología lukácsiana es preciso adentrarse aún más en el argumento. Para todo lo que sigue hay que tener presente que el trabajo no es solamente la actividad a través de la cual cobra existencia y sentido la vida social, sino que además es el modelo de la vida social en general. "El trabajo puede ser considerado, pues, como fenómeno originario (Urphänomen), como modelo (Modell) del ser social" (2004, p. 59). El carácter originario del que aquí se habla va más allá de una reafirmación del trabajo como fundamento dinámico de esa nueva forma del ser que es el ser social. El trabajo es, en sentido estricto, "el modelo de toda praxis social, de todo comportamiento social activo" (2004, p. 103). Esto significa que todas las acciones sociales, desde las más simples hasta las más complejas, son consideradas como derivaciones de esa "forma originaria" (Urform) que es el trabajo. El "lenguaje", el "valor", el "deber", y hasta la "libertad" misma tienen su génesis ontológica en el proceso de trabajo. Para decirlo todo, el trabajo aparece aquí como el origen y el paradigma de la socialidad. El ser social asume su así llamada "forma auténtica" (eigentliche Gestalt), vale decir, la "humanidad" en cuanto síntesis de la "individualidad" y del "género", como resultado de un largo y sinuoso proceso que tiene su punto de arranque en el salto cualitativo representado por el pasaje del animal al hombre a través del trabajo consciente.

Las sospechosas implicaciones de esta tesis y del lenguaje mismo en la cual está expuesta ameritan un análisis mucho más extenso que el que se puede ofrecer aquí. La reducción aplastante de la socialidad al proceso de trabajo permanece como una de las cuestiones más problemáticas de la ontología lukácsiana, pero también de sucesivas ontologías marxistas del ser social. Por eso mismo, resulta sorprendente que una tesis semejante admita al mismo tiempo una serie de principios que, en lugar de promover el reduccionismo, tienden a ampliar los horizontes de la teoría marxiana. Una lectura deconstructiva del texto de Lukács debería poner al descubierto una serie de supuestos, esquemas jerárquicos y oposiciones conceptuales que emparentan su discurso con el de la metafísica clásica al que precisamente su ontología del ser social pretende dejar atrás. No obstante ello, en el marco de una reevaluación de la temática ontológica en la historia reciente del marxismo es importante ponderar los aportes críticos y las novedades que introduce esta perspectiva. 
En este sentido, quizás lo primero que hay que señalar es que la investigación de Lukács rechaza toda explicación teleológica del desarrollo histórico-social. Como escribe en el texto de la conferencia: "Todo acontecimiento social procede de posiciones teleológicas individuales, pero posee un carácter puramente causal" (2004, p. 45). Lukács insiste una y otra vez sobre la importancia de esta "contradicción" o "discrepancia interna entre las posiciones teleológicas y sus consecuencias causales" que está en la base del ser social. Al recusar toda interpretación teleológica de la historia, toca un punto neurálgico de la discusión entre los marxistas de la época. Desde su punto de vista, el primer principio de la ontología de Marx es la historicidad del ser. El proceso histórico del ser social surge de la unidad, en sí misma contradictoria, entre teleología y causalidad, entre libertad y necesidad. En consecuencia, la historia no se desarrollaría en un sentido único y predeterminado, sino más bien en sentidos múltiples, donde, por lo demás, "el predominio fáctico de los elementos y tendencias materiales" no anula la influencia constante del "factor subjetivo" (Lenin). Esta forma de entender el proceso histórico entraña asimismo una crítica del determinismo económico propio de la ortodoxia marxista. Lukács niega de manera explícita el carácter "naturalmente necesario" del desarrollo económico en un sentido unívoco y, en simultáneo, afirma un conocimiento basado exclusivamente en explicaciones post festum.

A contracorriente de una idea por entonces muy en boga entre los teóricos marxistas de Occidente, Lukács cuestiona el supuesto antagonismo entre un joven Marx, filósofo, y un Marx maduro, consagrado a la economía. Según aquel, entre un período y el otro existe una marcada continuidad, que se manifiesta en la coexistencia de ciencia y ontología. En su análisis, observa de entrada la "situación paradójica" que plantea la ontología marxiana. Por un lado, los enunciados de Marx remiten constantemente a la pregunta por el ser, pero por otro lado, la cuestión nunca se plantea en términos estrictamente ontológicos, sumado al hecho, nada menor, de que aquel nunca tuvo la pretensión de crear un sistema filosófico. Esto no le impide a Lukács aventurar la tesis de que existe una ontología en Marx, y que esta, lejos de circunscribirse a los escritos filosóficos de juventud, como se podría creer con facilidad, se despliega a lo largo y a lo ancho de toda su obra, desde la tesis doctoral sobre los antiguos materialistas, donde ya sería posible rastrear sus primeras reflexiones ontológicas, hasta El capital, pasando por la Contribución a la crítica de la economía política, los Grundrisse y tantos otros textos. Huelga decir que la investigación de Lukács, con mayor o menor consideración según los casos, pero siempre con la mayor rigurosidad, se detiene en todos ellos.

Consciente del acontecimiento que la obra de Marx representa en la historia de la teoría y de la práctica, Lukács reconoce en la Ontología lo que pocos marxistas en aquella época estaban dispuestos a reconocer, entre otras cosas, que el proceso histórico es causal y no teleológico, que lo económico y lo extra-económico se condicionan mutuamente aun si la economía termina por resultar preponderante y, en suma, que la realidad consiste en un encuentro heterogéneo de relaciones y fuerzas en tensión permanente. Con todo, continúa aferrado a un concepto de 
"totalidad" (Totalität) poco compatible con esta lectura heterodoxa de las principales categorías de la teoría marxiana. ${ }^{9}$ En la Ontología, afirma que la concepción ontológica de Marx es contradictoria con cualquier reivindicación de sistema, cerrado y estático por definición. De ahí que cada vez que invoca la "totalidad del ser social" se vea obligado a aclarar enseguida que se trata de una "totalidad escalonada", "móvil", "dinámica": "[u]nidad de complejidad y de procesualidad" (2007, p. 89). Lukács destaca permanentemente la naturaleza compleja, procesual y relacional de la vida social, sin que esto le impida, en un gesto metafísico, reafirmar a la vez la primacía del "todo" sobre las "partes": "la concepción ontológicamente justa del ser, debe partir siempre de la heterogeneidad primaria de los elementos singulares, de los procesos, de los complejos, unos respecto a otros, y al mismo tiempo de la obligatoriedad de su íntima y radical copertenencia, en una totalidad social histórico-concreta" (2007, p. 127). De este modo, la heterogeneidad de las partes, y su interacción misma, queda subsumida a la totalidad del ser social, esto es, a la totalidad del género humano con su entorno o, dicho aún de otro modo, a la totalidad de la sociedad. Lo que resulta problemático en este planteo no es solamente la apelación a una categoría que, como es sabido, resulta incompatible con un pensamiento verdaderamente crítico, sino también el hecho de que Lukács termina por confirmar la oposición entre lo individual y lo social, cuando Marx se encarga de cuestionarla o al menos de resistirla en numerosos escritos. La extensa y dura crítica a las ontologías que, según Lukács, ignoran la historicidad del ser y toman por fundamento al individuo, no es seguida ni precedida por una crítica a las ontologías holistas. Y esto por la sencilla razón de que su propia ontología del ser social se inscribe entre estas últimas aun cuando no lo explicite en ningún momento.

Todavía habría mucho para decir sobre estas mismas cuestiones y sobre otras que aquí ni siquiera se han rozado, en particular, aquellas más directamente relacionadas con los capítulos de la Ontología dedicados a la reproducción, la ideología y la alienación. Pero de momento no se puede ir más lejos. Con esta lectura de algunos motivos centrales de la ontología lukácsiana se quiso llamar la atención sobre la riqueza hermenéutica de un texto que hoy comienza a ser merecidamente valorado y, asimismo, realizar algunas observaciones críticas que irán cobrando relevancia a medida que se avance en el análisis de otras interpretaciones sobre Marx y la cuestión del ser social.

\section{Gould}

La aparición del libro de Carol Gould, Marx's Social Ontology: Individuality and Community in Marx's Theory of Social Reality (1978), representó una verdadera novedad en el campo de la teoría marxista. Como se ha indicado, en aquel momento la ontología de Marx no era un tema de discusión. Pocos autores lo

\footnotetext{
${ }^{9}$ Sobre los usos y significados de este concepto en la obra de Lukács, véase (Jay, 1984).
} 
habían problematizado, entre ellos Lukács, claro está, aunque su Ontología todavía no había sido editada integralmente en lengua original. Sin embargo, para ese entonces ya circulaban ediciones parciales de la obray había traducciones de las mismas, algunas de las cuales son citadas por Gould. En cualquier caso, si en su momento este libro representó una novedad no fue solamente porque trataba un tema con escaza presencia en el debate teórico, sino también, precisamente, porque su explicación de la ontología social de Marx difería, en puntos decisivos, de la explicación ofrecida por Lukács.

La autora presenta la obra de Marx como una "transformación radical de la filosofía tradicional". Esta transformación se debería a la síntesis lograda por Marx "de la filosofía sistemática y de la teoría social". Gould entiende esta síntesis como una "ontología social", como una "teoría metafísica de la naturaleza de la realidad social" (1983, p. 7). Al igual que Lukács, considera que la ontología marxiana no es explícita sino implícita, de ahí que su exégesis implique una reconstrucción de los argumentos de Marx donde la ontología está presupuesta. Y si bien, según ella, la concepción ontológica de Marx puede encontrarse en todos sus trabajos teóricos, habría un texto donde la misma aparece más claramente que en cualquier otro. Este texto es los Grundrisse o Elementos fundamentales para la crítica de la economía política, de 1857-1858, a cuyo análisis está consagrado el libro.

También al igual que Lukács, Gould ve una continuidad entre los aspectos filosóficos y los aspectos científico-sociales del trabajo de Marx. Justamente, la ontología social no sería otra cosa que la síntesis de estos dos aspectos tan a menudo escindidos en las interpretaciones de la época. Ahora bien, dada la novedad, pero también la dificultad y hasta la susceptibilidad del tema en cuestión, ya en la Introducción se especifican los dos sentidos en que será utilizada la expresión "ontología social". "Puede significar el estudio de la naturaleza de la realidad social, esto es, la naturaleza de los individuos, instituciones y procesos que componen la sociedad [...] O bien, [...] puede significar ontología socializada, o sea, un estudio de la realidad que se refleja en las raíces sociales de los conceptos de esta realidad" (1983, p. 12). Este segundo sentido de la expresión refiere al hecho, destacado con insistencia por Marx, de que los enunciados teóricos están condicionados histórica y socialmente. No se trata, pues, de dos sentidos excluyentes. Más bien, ambos confluyen en una definición de la ontología social entendida como "el análisis de la naturaleza de la realidad social por medio de categorías socialmente interpretadas" (1983, p. 13).

En términos generales, al menos, el enfoque de Gould no parece estar muy alejado del de Lukács. No obstante, ya en esta primera aproximación a la ontología social, y particularmente en lo que hace al primero de sus sentidos, se revela una diferencia notable. Entre los elementos que componen la sociedad Gould sitúa a los individuos en primer lugar, seguidos por las instituciones y los procesos. En efecto, según su punto de vista, Marx es el creador de una ontología que "ve al individuo como intrínsecamente social y comunal, pero que también considera al individuo como el ente fundamental de la sociedad". Lukács, por el 
contrario, rechaza de plano cualquier prioridad ontológica del individuo sin por ello hacer explícita su toma de partido epistemológica por la sociedad.

No se trata, como quizás podría creerse, de una simple diferencia de matiz. Gould comienza el primer capítulo de su libro afirmando que "para Marx, las entidades fundamentales que componen la vida social son individuos en relaciones sociales" (1983, p. 25). Esto equivale a decir, en primer lugar, que la ontología de Marx da prioridad a los individuos -interpretación que no sólo difiere de la lectura de Lukács, sino que se opone abiertamente a la interpretación marxista dominante según la cual la sociedad prima sobre el individuo-, y luego, que estos individuos son inseparables de las relaciones sociales que mantienen entre sí. Desde este punto de vista, la obra de Marx representa una transformación radical de la ontología tradicional. No tanto por el hecho de que los elementos fundamentales de su ontología sean los individuos, sino más bien por el hecho de que estos individuos reales se encuentran en relaciones sociales en cambio permanente. Las relaciones en las que se encuentran los individuos varían históricamente. A cada momento de la historia y más concretamente a cada modo de producción le corresponden formas características de relaciones sociales. De ahí que las individualidades, entendidas como los principios fundamentales de la ontología marxiana, sean entidades "históricamente cambiantes" y no "entidades fijas".

A partir de esta primera afirmación, Gould concluye que "la teoría de Marx de la naturaleza de la realidad social es al mismo tiempo una teoría del cambio social. Esto es, su ontología filosófica misma es inseparable de la descripción aplicada del desarrollo social e histórico" (1983, p. 57). Y enseguida se apresura a aclarar que aun si se puede hablar de una lógica histórica del desarrollo de la realidad social, eso no quiere decir que Marx imponga una lógica a priori a la realidad social. De este modo, hace una diferencia tajante entre la dialéctica de Marx y la dialéctica de Hegel: el primero, a diferencia del segundo, rechaza la necesidad lógica del desarrollo y hace depender los hechos históricos de las acciones de individuos concretos y formalmente libres. En consecuencia, la ontología de Marx no podría ser pensada separadamente de su concepción histórica.

Una vez planteadas las premisas generales, Gould se dedica a argumentar en favor de su interpretación de la ontología social de Marx. ¿Qué implica considerar a los "individuos en relación" como las entidades fundamentales de la vida social? ¿Acaso esto significa que los individuos tienen el mismo estatuto ontológico que las relaciones existentes entre ellos? Gould no evita entrar en estas escabrosas cuestiones, entre otras razones, porque es consciente de que la originalidad y la radicalidad del planteo ontológico de Marx depende en buena medida del papel que juegan en él las relaciones sociales. Este hecho, confirmado por numerosos pasajes de las Tesis sobre Feuerbach y de los Grundrisse donde Marx a un mismo tiempo critica la oposición entre "individuo" y "sociedad" y reafirma la importancia de la "relación", lleva a Gould a buscar una forma alternativa de pensar la ontología social, esto es, una ontología que no sólo tenga en cuenta las relaciones sociales sino que les conceda el lugar prominente que hasta entonces no habían tenido. 
Sin duda, su apuesta es arriesgada. Intenta mostrar que "los conceptos 'individual' y 'relación' no son conceptos separables, y que Marx considera la separación de los individuos de sus relaciones [...] como una abstracción conceptual de la realidad concreta" (1983, p. 64). Esta simple afirmación la posiciona en un lugar diferente a los intérpretes anteriores. Sin embargo, dicha afirmación no impacta en su argumento ontológico. Para Gould, los individuos son tan "reales" como las relaciones pero en última instancia las segundas dependen de los primeros: "las relaciones no son irreales; más bien, existen enlos individuos relacionados y a través deellos, o como propiedades relacionales deesos individuos" (1983, p. 65). Por un lado, afirma la inseparabilidad de los individuos y las relaciones, pero por otro, secundariza la relación desde el momento en que la transforma en algo inherente a los individuos, vale decir, en una propiedad de los mismos.

En este punto, como en algunos otros en los que aquí no puedo detenerme, la autora ratifica el discurso clásico sobre el ser. Según ella, Marx "sigue de cerca a Aristóteles", pues ambos —afirma - parten de "individuos concretamente existentes". Desde la perspectiva aristotélica, el ente individual, el individuo en sentido amplio, es modelo de la sustancia. En Categorías —el texto de Aristóteles citado por Gould-, la sustancia en sentido estricto significa un "esto", lo que es "indivisible y numéricamente uno"; mientras que los accidentes, es decir, los predicados o propiedades de la sustancia, significan un "de tal cualidad", abarcando todo lo que se dice de los individuos o bien lo que se encuentra en ellos. Aristóteles diferencia a su vez entre sustancia primera (el "esto", el individuo) y sustancias segundas (la especie y el género a la que pertenece el individuo), y distingue nueve accidentes entre los cuales se encuentra la relación. Sin ir más lejos, lo que se deduce fácilmente de este esquema es la prioridad del individuo y la dependencia de los accidentes respecto de la sustancia primera. Leemos en Categorías: "si no hubiese sustancias primeras, sería imposible que existiera alguna de las restantes [entidades]. Pues todas las demás, o bien se dicen de las sustancias primeras como de sujetos, o bien se encuentran en ellas [como en] sujetos; de modo que, si no hubiese sustancias primeras, sería imposible que existiese alguna de las demás entidades" (2009, 2b6a-2b6c).

Según Gould, la prioridad y la dependencia que Aristóteles afirma en Categorías, Marx vendría a confirmarla en su propia ontología. La expresión "individuos en relación", en el sentido ontológico en el que ella la utiliza, presupone que los individuos son las sustancias primeras y la relación (o lo social) un accidente que acaece a dichos individuos. Nada distinto de lo que sucede en el discurso sustancialista. El punto en el que Marx se separa de Aristóteles — siempre según Gould- es que aquel no concibe la naturaleza o esencia humana como algo fijo y dado de antemano, sino como algo creado por los propios individuos en su actividad, lo cual "eventualmente lleva a la concepción de una esencia cambiante y en desarrollo" (1983, pp. 67-68). La socialidad, en cuanto modo de ser del hombre, cambia y se desarrolla constantemente puesto que es indisociable de la realidad histórica, económica, política y social en la que los hombres viven en cada momento. 
Es evidente que, en esta interpretación, los individuos no poseen el mismo estatuto ontológico que las relaciones que guardan entre sí. Gould distingue con toda claridad entre, por una parte, el individuo, entidad primaria, constituyente de la realidad social y por lo tanto ontológicamente independiente, y, por otra parte, la relación, entidad secundaria, constituida por la actividad del individuo y por lo tanto ontológicamente dependiente de la existencia de este último:

[...] para Marx, aunque dichos individuos no existen separados de sus relaciones, y de hecho se desarrollan y cambian por medio de estas relaciones, la existencia y forma de actividad de estos individuos es la presuposición ontológica de las relaciones en las que entran. Estos individuos, que según Marx son agentes, pueden considerarse como constituyentes de estas relaciones por su actividad, y, en consecuencia, no pueden verse como productos de estas relaciones. Así, estos individuos tienen una condición ontológica fundamental, y no han de ser considerados como meros nudos de relaciones o como constituidos totalmente por sus relaciones (1983, pp. 71-72).

Como se desprende de lo anterior, entre los individuos y sus relaciones media aún la actividad de estos individuos, que es presupuesto ontológico de sus respectivas relaciones. Al margen de la dificultad, si no de la imposibilidad, de imaginar la originariedad de cualquier actividad humana respecto de las relaciones sociales, todavía hay que preguntarse a qué actividad se refiere Gould específicamente. Pues no se trata de la actividad en general, no se trata de la práctica o de la praxis sin más, nociones que, como es sabido, sirven para describir una variedad infinita de acciones transformadoras. Gould, al igual que Lukács, considera puntualmente y de manera exclusiva la actividad del trabajo.

También en esta interpretación la ontología social de Marx deviene una ontología del trabajo, entendiendo a este último, fundamentalmente, como una "actividad en la cual los individuos se crean a sí mismos o llegan a ser lo que son" (1983, p. 74). Los individuos son los cimientos de la ontología social, y se auto-producen, precisamente, por medio del trabajo. Gould no se limita a reproducir conocidas afirmaciones de Marx sobre este tema, como por ejemplo que el trabajo es la actividad distintiva de la especie humana, que el trabajo es un proceso de objetivación (es decir, un proceso en el cual el sujeto forma objetos y se ve transformado a sí mismo por ese mismo acto), o bien, que el trabajo es una actividad teleológica (es decir, finalista). Ciertamente, su lectura va mucho más allá. Según ella, el trabajo es el arquetipo de la acción y la creación humanas. Es "la actividad real o práctica del sujeto en el mundo" (1983, p. 94). No es un modo entre otros de ser y hacer en el mundo, sino el modo que explica y contiene a todos los demás: es "la actividad humana misma". La categoría de trabajo tiene aquí una centralidad evidente. A tal punto que los conceptos de libertad y justicia, a los que Gould dedica los dos últimos capítulos de su libro, también se encuentran determinados por el trabajo y la producción. Dicho de manera extremadamente sintética, la libertad positiva que Marx esboza en los Grundrisse 
sería una actividad productiva más que un estado del ser: "la actividad del trabajo mismo, concebido como una actividad de auto-realización" (1983, p. 145). Y la justicia concreta, la justicia en la esfera de la producción en tanto ideal de reciprocidad y de dependencia mutua entre los individuos, es concebida como una condición para el total desarrollo de la libertad.

En este caso, el privilegio del trabajo tiene una fuerte impronta teleológica. La plena realización de cada una de las nociones que resultan fundamentales en esta interpretación de la ontología social de Marx ("individuos", "relaciones", "trabajo", "libertad", "justicia", etc.) dependen de ciertas condiciones sociales que sólo se alcanzarían en la etapa del desarrollo histórico identificada con la comunidad comunista del futuro. Desde un punto de vista ontológico este tipo de razonamientos conducen a contradicciones insalvables. De ahí el enérgico rechazo de Lukács, en la Ontología, respecto de toda concepción teleológica de la historia.

A continuación, consideraré rupturas y continuidades entre los enfoques hasta aquí analizados y la ontología del ser social propuesta por Negri y Hardt.

\section{Negri y Hardt}

A lo largo de su extensa obra, Negri ha desarrollado un pensamiento ontológico singular. Los primeros indicios del mismo pueden rastrearse en su importante libro sobre Spinoza: La anomalía salvaje (1981). Allí empieza a delinearse una reflexión sobre la "ontología constitutiva, fundada en la espontaneidad de las necesidades, organizada por la imaginación colectiva" (Negri, 1993, p. 19), que encontrará su continuación y profundización en textos algo posteriores. La colaboración con Hardt es un verdadero punto de inflexión en este sentido. El trabajo de Dionisos (1994) es el primer libro que escriben juntos y aquel donde se ofrece una primera aproximación a la cuestión ontológica tal como será desarrollada posteriormente en Imperio (2000) y sus múltiples secuelas: Guías: cinco lecciones en torno a Imperio (2003), Multitud (2004) y Commonwealth (2009), entre otras.

El acercamiento de Negri a la ontología responde a la necesidad de llevar la teoría y la práctica políticas más allá de las limitaciones de la sociedad burguesa, por un lado, y del propio marxismo, por otro, en un contexto de fuertes tensiones internas y externas, individuales y colectivas, que lo llevó a repensar por completo la estrategia revolucionaria. ${ }^{10}$ El acercamiento a la ontología está asociado a la necesidad, tantas veces reclamada por Negri, de renovar la propuesta comunista para estar a la altura de los problemas que plantea el capitalismo contemporáneo. Este reclamo está dirigido tanto a lo que en la teoría marxiana se encuentra caduco por efecto de las transformaciones históricas, como al marxismo tradicional y, más específicamente, a lo que en él se encuentra superado tanto en

\footnotetext{
${ }^{10}$ Para un análisis sobre el contexto y las razones del "giro ontológico" en la obra de Negri, véase (Murphy, 2003).
}

(c) EMUI Euro-Mediterranean University Institute | Universidad Complutense de Madrid | ISSN 1578-6730 Asociada a Nomads. Mediterranean Perspectives | EMUI_EuroMed University Salento | ISSN 1889-7231 
la teoría como en la práctica. Como veremos, Marx y el marxismo - revisitados, cuestionados y relanzados- constituyen referencias ineludibles de este giro pero están lejos de ser las únicas.

La nueva ontología de Negri y Hardt se sostiene sobre tradiciones muy diversas. Primeramente, conviene tener en cuenta que los autores entienden la ontología como una concepción no dialéctica de la constitución de las relaciones sociales (2003, p. 110). Inspirados en una tradición de pensadores críticos que va de Spinoza a Deleuze, pasando por Nietzsche, Negri y Hardt se proponen elaborar un método alternativo a la negatividad dialéctica. Esto es, un método de constitución positiva. La ontología constitutiva comparte con la teoría política liberal la crítica de la "idea dialéctica de la totalidad, de la linealidad y la teleología del desarrollo histórico, de la propuesta trascendental de un bien común, así como de la subsunción de las subjetividades individuales y autónomas en un sujeto de autoridad centralizado" (2003, p. 111). Ambas son "teorías abiertas", vale decir, teorías de la apertura en sentido filosófico, histórico y político, pero esto es todo lo que comparten. Puesto que, como explican los autores, las filosofías liberales, al igual que las teorías políticas posmodernas, combaten la ontología. Como insinuaba al comienzo de este trabajo, ensayar una lectura ontológica de los fenómenos sociales no implica necesariamente suscribir una mirada metafísica de los mismos. En el fondo, son las determinaciones metafísicas del ser -lo que el ser siempre ha sido, es y será- aquello que liberales, posmodernos y marxistas rechazan cuando combaten la ontología. Precisamente, Hardt y Negri intentan demostrar que ese combate no es necesario. Al menos si se considera que el ser no es algo uno y único, necesario ni cerrado en sí mismo, sino más bien multiplicidad, contingencia y apertura. La ontología que comienza a esbozarse en este primer libro en co-autoría está inspirado muy directamente en la "ontología histórica del nosotros" de Michel Foucault, entendida como "genealogía de la constitución del ser social". La pregunta por el ser es la pregunta por nosotros mismos, es la pregunta acerca de cómo somos constituidos en tanto sujetos de conocimiento, sujetos de poder y sujetos morales de la acción (2003, p. 112). Se trata de una ontología constitutiva porque se entiende el ser como construcción y proceso incesante, abierto al acontecimiento, $y$, por lo tanto, sin ordenamientos a priori o a posteriori. Al decir de los autores, "[l]a ontología no es una teoría del fundamento. Es una teoría acerca de nuestra inmersión en el ser y de la construcción continua de éste" (2003, p. 112).

Por consiguiente, la constitución del ser social no es una operación abstracta, sino concreta, real. Aquello con lo que lidia esta teoría no es otra cosa que las prácticas sociales de los sujetos en el mundo. De ahí que Hardt y Negri, reafirmando el espíritu marxiano, se hayan referido a su proyecto en más de una ocasión como una "ontología materialista". Lo cual no fue un obstáculo para que ambos manifestaran su abierto rechazo por el materialismo dialéctico en su versión ortodoxa (Diamat) y, más generalmente, de la dialéctica como metodología. En relación con este último punto, vale la pena recordar que el método de constitución positiva reconoce la herencia de diversas corrientes marxistas de la década del '70 que rehusaban el pensamiento dialéctico, entre ellas la corriente creada en torno a 
los trabajos de E. P. Thompson en Inglaterra y J.-H. Krahl en Alemania, así como el movimiento operaista (obrerista) en Italia, del cual Negri fue uno de sus principales referentes teóricos (2003, p. 113).

En El trabajo de Dionisos se habían sentado las bases de un programa metodológico y político de largo alcance que cobraría toda su relevancia en un trabajo apenas posterior llamado a tener gran influencia en el campo intelectual global: Imperio. El argumento del libro es conocido. Dicho muy esquemáticamente, allí se describe la emergencia de un nuevo sujeto político con sus correspondientes lógicas de dominio y soberanía a través del análisis de las transformaciones sociales vinculadas a la globalización política, económica y cultural. Lo que me interesa subrayar aquí es lo que Hardt y Negri denominan "drama ontológico", esto es, la tensión entre el proceso de creación y destrucción del imperio como consecuencia del desarrollo de este último. Se nos dice que el "drama es ontológico en el sentido de que en este proceso se produce y reproduce el ser" (2002, p. 55). El drama consistiría en que dentro de este nuevo sujeto político denominado "imperio", y a expensas suyas, emerge el poder constitutivo de la "multitud" capaz de construir una historia y una política enfrentadas a la explotación capitalista sobre una "base ontológica alternativa". Justamente, esta base "se sustenta en las prácticas creativas y productivas de la multitud", entendiendo a esta última como un conjunto de singularidades heterogéneas y mutuamente relacionadas con capacidad de modelar un poder contraimperial. Nótese, por una parte, que este "sustrato ontológico" alternativo moviliza acciones contrapuestas al orden político-económico-cultural actual, y, por otra parte, que el mismo sustrato se encuentra "abierto a la crítica" y "representa el referente ontológico real de la filosofía o, mejor dicho, el campo propicio para una filosofía de la liberación" (2002, p. 56).

Aparentemente, este modo de ver las cosas dejaría los planteos anteriores muy atrás. El referente ontológico no es la "totalidad del ser social", como afirma Lukács, ni son los "individuos en relación", como afirma Gould. Para Hardt y Negri el referente ontológico son las "fuerzas subjetivas que actúan en el contexto histórico": "actividades, resistencias, voluntades y deseos que repudian el orden hegemónico" (2002, p. 56). Así, pues, la ontología positiva de la multitud aparece como alternativa enfrentada a la ontología negativa del imperio. La dualidad entre estas categorías se reproduce en todos los niveles de análisis. El poder constitutivo de la multitud representa un "nuevo sentido del ser" y el poder constituido del imperio es "privación del ser", puesto que la multitud "es la auténtica fuerza productiva de nuestro mundo social, en tanto que el imperio es un mero aparato de captura que vive a costa de la vitalidad de los pueblos" (2002, pp. 66-67). Desde esta perspectiva, el elemento fundamental de una nueva ontología alternativa es la productividad de la multitud en un escenario biopolítico global donde las diferentes esferas de la vida social tienden a confluir y solaparse.

No cabe duda de que la apuesta teórica de Hardt y Negri pretende ser novedosa y, en muchos sentidos, superadora. Para empezar, superadora de los marxismos tradicionales y sus respectivas metodologías, pero también y más ampliamente de las ficciones trascendentales de la filosofía política clásica. Para ello se sirven de 
un método no-dialéctico y radicalmente inmanentista del cual se desprende su ontología del ser social. No es mi intención discutir aquí el alcance general de las novedades teórico-prácticas que se introducen a lo largo del libro ni del carácter pretendidamente superador de las mismas. Mi único interés es llamar la atención sobre un hecho puntual y no por ello menor, a saber, que en el corazón de esta interpretación del ser social aparece intacto un supuesto compartido con las ontologías marxistas ya consideradas y que consiste en privilegiar la producción, y más específicamente el trabajo, dentro del conjunto de las prácticas sociales. Cabe preguntarse: ¿por qué si se reconoce desde el principio una trama ontológica hecha de múltiples actividades, resistencias, voluntades y deseos el peso del trabajo en la constitución ontológica de la realidad se vuelve tan determinante en el argumento de Imperio y de los libros que lo siguieron? ¿Por qué el trabajo de la multitud, y sólo él, es capaz de construir el nuevo sentido del ser que aquí se postula? ¿Por qué, en definitiva, esta primacía del trabajo sobre cualquier otra fuerza subjetiva?

Entre otras afirmaciones que apuntan en esta dirección, en Imperio puede leerse que "[c]uando la multitud trabaja, produce autónomamente y reproduce la totalidad del mundo de la vida. Producir y reproducir autónomamente significa construir una nueva realidad ontológica. En efecto, al trabajar, la multitud se produce a sí misma como singularidad" (2002, p. 342). A esta altura, la tesis del trabajo como modelo de la producción y la auto-producción humana no constituye ninguna novedad. Más bien todo lo contrario. Vale decir que es una constante de las ontologías marxistas. En el discurso de Negri y Hardt la "ontología social" también termina por remitir a la "ontología del trabajo". Incluso cuando se refieren a otros registros ontológicos (lo "común", la política, etc.), finalmente vemos como estos terminan por quedar subordinados a la lógica del trabajo y la explotación actuales. Para comprender esta subordinación hay que entender el punto de partida de todo el argumento. Dicho de manera sucinta y haciendo la economía de una serie de razonamientos y de referencias teóricas que aquí me veo obligado a dejar de lado por motivos de espacio, el argumento general parte de lo que es, de lo que existe. Para los autores, la realidad en términos ontológicos está signada fundamentalmente por las transformaciones que tienen lugar actualmente en el mundo del trabajo. Una de estas transformaciones, acaso la principal, es la transición de un paradigma productivo donde primaba el trabajomaterial a uno donde prima el trabajoinmaterial (mental o intelectual). ${ }^{11} \mathrm{En}$ la interpretación de Negri y Hardt, el pasaje del trabajo material al inmaterial (o como también lo llaman: el pasaje del fordismo al posfordismo) constituye una marca de nuestro tiempo que deriva en la clara hegemonía del segundo. Ahora bien, el trabajo inmaterial no indica solamente un nuevo régimen de trabajo, una transformación específica en el modo de concebir y ejecutar la producción de mercancías. Aquel

\footnotetext{
${ }^{11}$ Esta hipótesis había sido delineada por Marx en el "Fragmento sobre las máquinas" de los Grundrisse (Marx, 2011, pp. 227-230). Maurizio Lazzarato y Paolo Virno, entre otros autores vinculados al post-operaismo italiano, también se han servido de esta hipótesis para desarrollar sus propias interpretaciones acerca de las transformaciones en los modos actuales de la organización del trabajo.
} 
excede por mucho el terreno de la producción desde el momento en que comprende "el conjunto de las actividades intelectuales, comunicativas, relacionales y afectivas expresadas por los sujetos y los movimientos sociales" (Negri, 2004, p. 75). En otras palabras, el trabajo ya no se diferencia de la vida. Nada de lo que es o de lo que existe sería ajeno al trabajo. En verdad, no es tanto que el trabajo en la época de su inmaterialidad, es decir, en la época del capitalismo cognitivo, exceda el terreno de la producción, sino que la producción en sus condiciones actuales modela la vida hasta en sus más mínimos detalles. El trabajo y la producción ya no serían un ámbito del ser social, ni siquiera su ámbito por excelencia, sino el ser social en su conjunto, tal como queda confirmado en frases como esta: "el trabajo [...] ha ocupado toda la vida" (Negri, 2004, p. 83). O, por ejemplo, esta otra: "no hay nada que esté fuera de la producción, todos estamos aquí adentro" (Negri, 2004, p. 90).

Comprender el trabajo ya no desde un punto de vista económico, sino desde un punto de vista omnicomprensivo, requiere adoptar una clave de lectura que los autores denominan "biopolítica", de acuerdo con una particular interpretación de la categoría popularizada por Foucault. Esta clave de lectura los lleva a considerar la vida y el trabajo como una unidad indiferenciada que, a su vez, sirve de base a la ontología que proponen como alternativa: "La ontología social deviene, así, biopolítica. Esto quiere decir que el proceso productivo reviste a la misma vida, entendiendo por proceso productivo el conjunto de conocimientos y pasiones, de lenguajes y afectos que conforman las subjetividades" (Hardt y Negri, 2004, p. 195). La ontología social se convierte en biopolítica porque lo que se pone en juego a través de las recientes mutaciones en el paradigma productivo es ni más ni menos que el ser social, o sea, nosotros mismos. Si esta ontología del ser social resulta una propuesta alternativa, lo es con relación a aspectos puntuales de la metodología puesta en práctica por las grandes teorías políticas, marxistas o de otro tipo. Lo cual no impide detectar en ella una vieja y obstinada tendencia de la cual es deudora buena parte de los marxismos de todos los tiempos, que consiste en atribuirle a la actividad productiva un estatuto preferencial con relación al resto de las actividades que los sujetos llevan adelante y de las que son capaces en su existencia en común. Dentro de la escena del pensamiento marxista contemporáneo, la interpretación de Balibar sobre esta cuestión capital irrumpe como una verdadera excepción. A ella, pues, está dedicado el próximo apartado.

\section{Balibar}

Tal vez el nombre de Balibar sorprenda en esta serie. Quienes conocen su extensa trayectoria, saben que la ontología de Marx no forma parte de sus principales inquietudes. Sin embargo, la potencia y el alcance de sus afirmaciones, así como la originalidad de su toma de partido, amerita como mínimo una lectura cuidadosa de aquellos textos donde se ha pronunciado al respecto. 
Su primer libro, y seguramente el más leído hasta hoy, es el ya clásico Para leer El capital (1965), escrito en colaboración con L. Althusser, R. Establet, P. Macherey y J., Rancière. Inútil insistir en la importancia y el carácter teórico fundacional de este texto para toda una época del marxismo occidental. Casi tres décadas y al menos una decena de publicaciones -entre las cuales cabe destacar Cinco estudios de materialismo histórico (1974), Sobre la dictadura del proletariado (1976), Spinoza y la política (1985), Raza, nación y clase, en colaboración con I. Wallerstein (1988) y Escritos por Althusser (1991) - median entre Para leer El Capital y la aparición de otro libro suyo, sin duda menos conocido, donde por primera vez aparece problematizada la ontología marxiana. Este se titula La filosofía de Marx, se editó en 1993 y se reeditó en versión corregida y aumentada en 2001 y 2014.

La tesis que allí se pone a prueba es la siguiente: "no hay ni habrá jamás filosofía marxista; en cambio, la importancia de Marx para la filosofía es más grande que nunca" (Balibar, 2006, p. 5). La expresión "filosofía marxista" refiere tanto a la concepción del mundo asumida por un sinnúmero de movimientos políticos y sociales como a una supuesta doctrina ideada por Marx. Si no hay ni habrá filosofía marxista es porque los enunciados filosóficos de Marx nunca dieron lugar a un sistema coherente y unificado. Según Balibar, dichos enunciados ponen en entredicho la idea misma de sistema provocando "una oscilación permanente entre el más acá y el más allá de la filosofía” (2006, p. 8). Al mismo tiempo que postulaba una tesis de amplio alcance teórico, Balibar buscaba instalar y defender una posición para comprender el presente. Dado que con la caída del Muro de Berlín habían caído los sistemas políticos identificados con las ideas de Marx, uno de los peligros latentes en la nueva configuración mundial era el olvido de su legado. El escrito de Balibar emerge en ese contexto y desde sus primeras líneas hace explícito su cometido: "[l]a idea general de este pequeño libro es comprender y hacer comprender por qué se seguirá leyendo a Marx en el siglo XXI: no sólo como un monumento del pasado, sino como un autor actual, por los interrogantes que plantea a la filosofía y los conceptos que le propone" (2006, p. 5). Como se verá enseguida, entre los interrogantes y los conceptos que pone a disposición de la discusión filosófica contemporánea aparece comprometido el asunto de la ontología.

La interpretación de Balibar difiere de las anteriores en varios aspectos. El más visible, quizás, es el lugar que le asigna a la ontología. Lejos de constituir la piedra angular que nos permitiría comprender la obra de Marx en su conjunto, para Balibar la cuestión ontológica aparece acotada a las Tesis sobre Feuerbach. Escritas por Marx en 1845, las Tesis... recién se conocieron después de su muerte. Vieron la luz gracias a Engels, quien las encontró en un viejo cuaderno de Marx y las publicó en 1888 como apéndice a su texto "Ludwig Feuerbach y el fin de la filosofía clásica alemana". Balibar dedica numerosas páginas a interpretar el contenido de las Tesis... y, en particular, aquello que allí resulta decisivo para comprender la compleja relación entre Marx y la filosofía. De las once tesis sobre Feuerbach, la sexta tesis ocupa un sitio aparte en esta interpretación. Allí, precisamente, se reconoce el esbozo de una ontología singular. Puesto que en 
este libro así como en un texto posterior que comentaré más adelante Balibar propone un minucioso examen textual de la sexta tesis, sería conveniente recordarla en toda su extensión:

Feuerbach resuelve la esencia religiosa en la esencia humana. Pero la esencia humana no es algo abstracto e inmanente a cada individuo. Es, en su realidad, el conjunto de las relaciones sociales (Aber das menschliche Wesen ist kein dem einzelnen Individuum inwohnendes Abstraktum. In seiner Wirklichkeit ist es das ensemble der gesellschaftlichen Verhältnisse).

Feuerbach, quien no entra en la crítica de esta esencia real, se ve, por tanto, obligado:

1. ${ }^{\circ}$ a prescindir del proceso histórico, plasmando el sentimiento religioso de por sí y presuponiendo un individuo humano abstracto, aislado.

2. 'La esencia sólo puede concebirse, por tanto, de un modo "genérico", como una generalidad interna, muda, que une de un modo natural a los muchos individuos (Marx, 1969; Marx, 1985, p. 667).

El primer punto sobre el que Balibar llama la atención es que aquí Marx intenta responder a la pregunta por la esencia o la naturaleza humana de un modo novedoso y sin duda radical. Como es sabido, no es esta la única ocasión en que Marx ofrece una respuesta a esta vieja pregunta. En todo caso, lo que sorprende de su respuesta es que el hombre no sea definido, como en otras oportunidades, por su relación con el trabajo o la conciencia. Lo que afirma la sexta tesis es que "la esencia humana no es algo abstracto e inmanente a cada individuo", es decir, que no se corresponde con una abstracción universal, general o genérica que sería inherente a cada uno de los individuos, tal como los filósofos suelen representársela desde la Antigüedad. Por el contrario, la esencia humana "[e]s, en su realidad, el conjunto de las relaciones sociales", y por relaciones sociales hay que entender aquí algo concreto que no tiene lugar simplemente dentro o fuera de los individuos sino más bien a través de los individuos.

Según Balibar, con esta definición Marx desplaza radicalmente la comprensión habitual del "hombre" y de la "esencia", al tiempo que impugna las posiciones filosóficas realistas y nominalistas, por un lado, y los puntos de vista individualistas y holistas, por otro. Si se tiene en cuenta el fundamento del que parten cada una de estas perspectivas, ya sean los universales o los particulares, ya sea el individuo o el todo, es evidente que ninguna de ellas está en condiciones de captar el carácter esencialmente relacional de la existencia social. He aquí la apuesta hermenéutica de Balibar, el argumento general a partir del cual introducirá la cuestión ontológica. Precisamente, el hecho de que la sexta tesis identifique la esencia humana con el conjunto de las relaciones sociales, habilita a una interpretación donde Marx se aleja de las ontologías sustancialistas tradicionales y se acerca a una "concepción de la relación constitutiva, que desplaza la cuestión 
de la esencia humana a la vez que le brinda una respuesta formal" (Balibar, 2006, p. 37). Esta concepciónque hace valer la primacía y el carácter constitutivo de las relaciones sociales es lo que Balibar llama una "ontología de la relación" o una "ontología transindividual". Efectivamente, los términos relación y transindividual son intercambiables. Balibar los utiliza indistintamente, si bien explica que el segundo viene a echar luz sobre el primero. En general, se cree saber demasiado bien qué es una relación. Tal vez por eso es preciso acudir a un nuevo término que venga a descubrir lo no-sabido de la relación. La palabra "transindividual" es utilizada por pensadores contemporáneos como Alexandre Kojève, Jacques Lacan y Gilbert Simondon para describir una realidad que no es ni individual ni social, sino más bien individual y social a la vez. Para Simondon, que es la referencia directa de Balibar en esta materia, la realidad transindividual es, al mismo tiempo, psíquica y colectiva, interior y exterior. Lo transindividual tiene lugar entre los individuos y es lo que los hace ser o estar juntos. ${ }^{12}$

Desde el punto de vista de Balibar, la importancia y la novedad de una ontología de la relación o de lo transindividual radica en que "sustituye la discusión sobre las relaciones del individuo y el género por un programa de investigación de esta multiplicidad de relaciones, que son otras tantas transiciones, transferencias o pasajes en los que se hace y se deshace el vínculo de los individuos con la comunidad y que, como respuesta, los constituye" (2006, p. 38). De lo dicho hasta el momento se desprenden dos tesis importantes que habrá que profundizar. Primera tesis: son las relaciones las que constituyen, en sentido ontológico, tanto lo individual como lo social, si acaso se puede seguir hablando en estos términos. Pues la primacía de la relación anula la dualidad entre estos polos y, simultáneamente, impide seguir pensando al "individuo" o a la "sociedad" como los fundamentos lógicos y epistemológicos de la vida en común. Segunda tesis: las relaciones de las que se habla aquí involucran prácticas múltiples y heterogéneas. Ningún tipo de relación social, ningún tipo de práctica general o particular domina sobre las demás, ni siquiera las "relaciones sociales de producción" que se crean entre las distintas clases. Todas las instancias de la "existencia humana" —Balibar habla de "lenguaje, trabajo, amor, reproducción, dominación, conflictos, etcétera"- se distinguen y se relacionan entre sí sin que ninguna de ellas se vuelva predominante. Por lo tanto, se puede suponer que el conjunto de las relaciones sociales a las que Marx se refiere en la sexta tesis no implican determinación alguna.

Sin duda, la interpretación de Balibar plantea una serie de cuestiones que alteran esencialmente el modo en que se suele leer la ontología de Marx. Pero es necesario reconocer que dicha interpretación era una invitación al análisis más que un análisis propiamente dicho, en la medida en que su libro no profundiza la investigación sobre la naturaleza de las relaciones sociales. Balibar recién volvió a tratar el problema casi 20 años más tarde en un artículo titulado "¿Antropología filosófica u Ontología de la relación? ¿Qué hacer con la 'VI tesis sobre

\footnotetext{
${ }^{12}$ Véase (Simondon, 2009). Sobre la historia del término y sus diferentes usos y significados, véase (Balibar y Morfino, 2014).
} 
Feuerbach'?"13 Aquí se embarca nuevamente en un comentario de la sexta tesis, pero esta vez mucho más detallado y meditado que el anterior. Su objetivo, declarado desde el comienzo, es poner a prueba nuestra comprensión del texto de Marx haciendo especial hincapié en la palabra Verhältnis, comúnmente traducida al francés por "rapport" o "relation" y al castellano por "relación". Se trata de un artículo minucioso y erudito que no pretendo ni puedo abarcar aquí en toda su extensión. Sólo voy a considerar algunos pasajes importantes que contribuyen al debate sobre la ontología social de Marx.

Balibar procede entonces a desglosar palabra por palabra la sexta tesis. Comienza por examinar la primera parte o, como él la llama, el "enunciado negativo" donde se dice lo que la esencia humana no es, para luego tratar el "enunciado positivo" donde se define la esencia humana como el conjunto de las relaciones sociales. Voy a detenerme en esta segunda parte. Lo primero que llama la atención de Balibar es el término Wirklichkeit, de procedencia hegeliana, el cual encontramos traducido habitualmente por "realidad" (como es el caso en la versión de W. Roces citada más arriba). El problema con esta traducción sería que da lugar a una "interpretación débil" donde la "realidad" se opone a la falsedad y queda automáticamente asociada a la verdad como adecuación a los hechos. No obstante, explica Balibar, en el contexto de la filosofía hegeliana Wirklichkeit sería la "efectividad", lo efectuado o lo producido, antes que la "realidad", la cual se designa con el término Realität. La "interpretación fuerte", que aquí se propone como alternativa a la anterior, invita a "pensar lo que identifica a la esencia con una efectuación o un proceso de realización 'en acto"': "el concepto de Wesen (ser o esencia) no tiene otro contenido que una actividad o un proceso, en otros términos una praxis" (Balibar, 2014, p. 219). De este modo, afirmar que la esencia humana es, en su realidad efectiva, el conjunto de las relaciones sociales, ya supone pensar el ser o la esencia como acción histórica y materialmente situada.

Al pasar al predicado del enunciado positivo, Balibar recuerda que en 1845 la expresión "relaciones sociales" era un invento recientemente introducido al lenguaje de la teoría social por las ideologías posrevolucionarias. A su vez, el concepto de relaciones sociales utilizado por los pensadores conservadores, liberales y socialistas de principios del siglo XIX es indisociable de la nueva ciencia de la "sociedad" a la que Auguste Comte dio en llamar sociología. Todas estas novedades en el plano de la teoría forman parte de una verdadera transformación epistemológica a la que el propio Marx pretendía contribuir. De acuerdo con Balibar, el uso del concepto de relaciones sociales por parte de Marx en 1845 implicaba tanto una embestida contra la especulación filosófica como un intento por comprender el nacimiento y el desarrollo histórico de los elementos sociales que definen al hombre.

\footnotetext{
${ }^{13}$ El artículo apareció por primera vez en inglés: (Balibar, 2012). Luego apareció en francés, aunque en una versión ligeramente modificada, como "complemento" a la nueva edición corregida y aumentada de La filosofía de Marx: "Anthropologie philosophique ou Ontologie de la relation? Que faire de la 'Vle Thèse sur Feuerbach'?”, en (Balibar, 2014).
} 
En el enunciado positivo hay una palabra extranjera que llama la atención de Balibar: la palabra francesa ensemble, traducida al castellano por "conjunto". Lo sorprendente no es tanto el recurso a un término francés en el medio de un enunciado escrito en alemán - son muchos los textos de Marx, especialmente borradores, donde se mezclan diferentes lenguas-, sino la elección particular de un término "agresivamente neutro o minimalista, por oposición a [...] todas las expresiones posibles (en alemán) que connotan la idea de que las relaciones sociales forman una totalidad, incluso una totalidad orgánica" (2014, pp. 231-232). Como se verá, aquí la palabra ensemble constituye la base de otra interpretación fuerte. Es el indicio de una nueva posibilidad interpretativa de la ontología social de Marx. De hecho, Balibar encuentra "tres significaciones positivas" a la elección de este término, cuyo primer y principal aporte sería "producir un efecto performativo de 'destotalización', deconstruyendo el efecto-totalidad" de la noción de ser o esencia (2014, p. 232). Estas tres significaciones son la horizontalidad, la serialidad y la multiplicidad de las relaciones sociales: horizontalidad puesto que no hay ningún tipo de jerarquía entre las relaciones sociales y que, por consiguiente, ninguna es más esencial que las demás; serialidad en el sentido de que las relaciones sociales forman una serie indefinida, una apertura que no admite clausuras ni determinaciones de ninguna clase; y multiplicidad (o heterogeneidad)ya que las relaciones son muchas y pertenecen a diferentes modalidades de la praxis social.

Ahora bien, si se relee el enunciado completo de la sexta tesis en la clave de lectura propuesta, rápidamente se pone en evidencia el carácter paradójico de la noción de esencia humana planteado por Marx. Como da a entender Balibar, parece más bien el puntal de una anti-ontología que el de una ontología en sentido convencional, visto que "en lugar de unificar una multiplicidad de atributos para hacer de ellos una totalidad, abre un campo indefinido de metamorfosis y de transformaciones históricas" (2014, p. 235). Este cambio sideral en el modo de comprender la noción de esencia, que ya no se identifica con nada parecido a una sustancia en el sentido aristotélico del término, es lo que permite hablar de una ontología marxiana de la relación o de lo transindividual.

Con todo, en este texto donde Balibar retoma y profundiza la tesis que ya había bosquejado en La filosofía de Marx también pone sobre aviso al lector respecto de un posible equívoco: habría que evitar interpretar la "ontología social" como una "ontologización de lo social" ya que se corre el riesgo o bien de sustancializar la "sociedad" en general o bien de sustancializar "lo social" en cualquiera de sus instancias particulares, dos variantes que no harían más que confirmar una lógica clásica. Más bien, se trata de "socializar la ontología", es decir, traducir las cuestiones ontológicas en cuestiones sociales o, si se quiere, relacionales. En resumidas cuentas, socializar la ontología es "una manera de pensar el hecho de ser/estar 'en relación' (être 'en rapport'), activamente y pasivamente, como la marca ontológica y la modalidad relacional constitutiva de lo humano" (2014, p. 237).

Del mismo modo, advierte Balibar, habría que evitar toda tentativa humanista por postular y definir al "hombre" antes de haber reflexionado lo suficiente sobre el 
carácter constitutivo de las relaciones sociales. Para ello no quedaría otra alternativa que comenzar por afirmar la condición necesariamente plural de la existencia humana. Pero para ser consecuente hasta el final con lo que supone una "ontología de la relación" no basta con reconocer el origen plural de las singularidades humanas, sino que también es preciso insistir en el hecho de que es a través de las relaciones sociales que se establecen las diferencias a partir de las cuales cada cual es lo que es $y$, asimismo, que son estas diferencias irreductibles lo que las singularidades tienen en común:

[...] las relaciones sociales siempre están interiormente determinadas como diferencias, transformaciones, contradicciones y conflictos, de manera lo suficientemente radical como para no dejar subsistir como "comunidad" o "ser-encomún" (Mitsein) más que las diferencias y la heterogeneidad misma que ellas crean (Balibar, 2014, p. 238).

\section{Convergencias, divergencias, alternancias}

A pesar de las enormes diferencias entre los planteos de Lukács, Gould, Negri, Hardt y Balibar, es preciso advertir que todos ellos comienzan por tomar distancia y criticar la representación corriente de la ontología como reflexión meramente especulativa, escindida de la historia. Hemos visto que la ontología no declarada que atraviesa la obra de Marx impacta de formas muy distintas en estos autores, pero en principio le permite a cada uno elaborar un cuestionamiento original respecto de aquello que la filosofía entiende por el ser, en particular cuando este entendimiento no toca o no es tocado inmediatamente por la socialidad. Esta cuestión es de la mayor importancia en la medida en que permite trazar un hilo conductor entre Marx y las distintas ontologías marxistas que acabamos de examinar. La crítica de la filosofía, su "supresión" y al mismo tiempo su "realización", tal como se exige en la "Introducción a la crítica de la filosofía del derecho de Hegel", no desemboca en ningún caso en el fin de toda filosofía sino, puntualmente, en el de aquella que es incapaz de pensarse a sí misma enraizada a la situación histórico-social de la que emerge. La crítica que emprende Marx, más que acabar con la filosofía tiene por objetivo poner al descubierto las relaciones que esta mantiene con lo que desde un punto de vista especulativo se considera como su "afuera", esto es, con las teorías y las prácticas económicas, sociales, políticas, etc. Los representantes de las ontologías analizadas abrazan y continúan por otros medios una contradicción inherente a la empresa marxiana, a saber, la de enfrentar con argumentos filosóficos la pretensión de la filosofía de apropiarse y dominar su "exterior" y, en una palabra, todo lo que no es ella misma, o sea, su "otro". De ahí la enorme tentación de interpretar esta empresa como una anti-filosofía y, en el límite, como una anti-ontología que, sin embargo, no termina por renunciar ni a una cosa ni a la otra. 
Más allá de esta contradicción, aceptada o no como tal pero en la que todos coinciden y que sirve a su vez de punto de partida a cada una de estas reflexiones, hemos detectado numerosas diferencias. La importancia de la ontología para Marx y el lugar que esta ocupa en su teoría, el fundamento lógico y epistemológico de la concepción del ser social, la comprensión del proceso histórico y de la historicidad del ser, la perspectiva metodológica adoptada y las motivaciones políticas puestas en juego en cada caso son algunos de los puntos en los cuales encontramos las más grandes divergencias. Sin por ello descartar, en estos y otros puntos, interesantes convergencias.

Los posicionamientos son muy variados, como ya hubo posibilidad de constatar. Sin embargo, hay una cuestión sobre la que me gustaría volver en la que si bien no hay completo acuerdo se puede decir que existe un amplio consenso. Me refiero al privilegio absoluto que detenta el trabajo frente a otras actividades y relaciones sociales de los individuos. Con la notable excepción de Balibar, todos los autores que hemos leído empiezan o terminan por reducir la ontología social de Marx a una ontología del trabajo o de la producción. Incluso entre quienes se han ocupado del tema muy parcialmente, sea a través de artículos o comentarios, prevalece esta misma tendencia. ${ }^{14}$ El propio Heidegger, en un texto en el que se refiere explícitamente a Marx y al marxismo, declara que "[l]a esencia del materialismo no consiste en la afirmación de que todo es materia, sino, más bien, en una determinación metafísica según la cual todo ente aparece como material de trabajo" (2001, pp. 53-54). La inmensa mayoría de quienes —marxista o noleyeron a Marx en clave ontológica, tienden a confirmar la interpretación que identifica el ser con el trabajo y la producción.

No es ninguna casualidad que Marx haya sido leído de esta forma unánimemente. Son numerosísimos los pasajes de su obra, especialmente a partir de La ideología alemana (1845-1846), donde se pone de manifiesto una identificación entre las "relaciones sociales" - relaciones que en las Tesis... no refieren a otra cosa que la praxis en el sentido más abarcador del término-y las "relaciones de trabajo", las "relaciones de producción" y las "relaciones de clase". En efecto, después de las Tesis..., Marx procede a especificar y determinar progresivamente el sentido general y hasta entonces indeterminado de las relaciones sociales. Desde entonces, el trabajo se convierte en la condición y el fundamento de la existencia social. En opinión de Balibar, cuya lectura sigue de cerca este movimiento, Marx tuvo "muy buenas razones" para actuar de este modo. Según da a entender, razones políticas o estratégicas más que razones propiamente filosóficas. "Si Marx no hubiera identificado de manera tan 'unilateral' las relaciones sociales con las relaciones de producción (y lo que deriva de ellas), quizás todavía estaríamos creyendo que lo que hace a una 'sociedad' es un espíritu, o una cultura, o un régimen político...” (Balibar, 2014, pp. 245-246). Quizás. En cualquier caso, sean

\footnotetext{
${ }^{14}$ Véase, por ejemplo, (Lachterman, 1996) y (Yu, 2009). También en este sentido remito a (Granel, 1968), donde sobre la base de una lectura minuciosa de los Manuscritos económico-filosóficos de 1844 y La ideología alemana Granel llega a afirmar que Marx identifica el "ser del ente" con la "producción" e incluso con la "industria": "Producción es, en la ontología marxista de los años 44/45, el término que designa el sentido mismo del ser" (1968, pp. 304-305).
} 
buenas o malas las razones de esta "reducción de complejidad", como la llama el mismo Balibar, lo cierto es que a partir de 1845-1846 subyace en los escritos de Marx una antropología y una ontología gobernadas por la noción de trabajo productivo.

Por lo demás, es perfectamente comprensible que la interpretación dominante de una teoría que le asigna a "lo económico" la importancia que todos conocemos considere el trabajo y la producción como conceptos fundamentales. En este sentido, es sintomático que aquellos pensadores que más avanzaron en la reformulación crítica de la teoría marxiana con el fin de mantenerla vigente llegaron a trastocar el significado del concepto de trabajo en aspectos cruciales, sin por ello modificar el lugar que este ocupa en la estructura general del discurso marxista. Un caso paradigmático de la operación que acabo de describir lo encontramos en los textos de Negri y Hardt. Como ellos mismos dicen y no se cansan de repetir, la crítica que dirigen a Marx no significa un alejamiento respecto de sus postulados básicos ni de sus conceptos fundamentales. De hecho, los "dos presupuestos de la ontología marxiana" se mantienen inalterados en sus propios análisis. Dichos presupuestos son más sencillos de lo que se podría esperar. "El primero es que el mundo está creado por el trabajo. El segundo es que este trabajo será siempre explotado mientras exista el capitalismo" (Negri, 2004, p. 81). Desde esta óptica, el mundo y el trabajo bajo las condiciones actuales del sistema capitalista no son los mismos que Marx había percibido en su momento. Sin embargo, eso no cambia en nada el hecho de que el mundo siga siendo, ante todo y sobre todo, producto del trabajo.

Balibar se desmarca claramente de esta posición o presuposición ontológica que convierte al trabajo en un fundamento determinante. Su interpretación de la ontología marxiana está acotada al contenido de las Tesis..., del que no se puede inferir ninguna prerrogativa del trabajo o de la producción sin violentar la indeterminación esencial que vincula la naturaleza humana al conjunto de las relaciones sociales. En este mismo sentido, es interesante remitir a un diálogo público que tuvo lugar en 2009 entre Balibar y Negri donde aquel le reprocha a este, entre otras cosas, el hecho de tener como "prerrequisito ontológico [...] la primacía absoluta, por no decir la unicidad, de la fuerza productiva como fundamento antropológico para la política y el cambio histórico" (Curcio y Özselçuk, 2010, p. 318). La objeción de Balibar a la reflexión ontológica de Negri podría resumirse del modo siguiente. Por una parte, sería un enfoque demasiado acotado para pensar las luchas sociales en la medida en que relega una gran cantidad de dimensiones ideológicas y problemas concretos (políticos, religiosos, culturales, etc.) que exceden el análisis de la fuerza productiva. Por otra parte, y como consecuencia de este enfoque unidimensional que lo lleva a ver al hombre como un animal productivo, su concepción del comunismo como estadio final de una creciente socialización del trabajo sería implícitamente teleológica y, por consiguiente, "completamente metafísica" (Curcio y Özselçuk, 2010, p. 318). Negri, por su parte, en principio se limita a negar estas acusaciones sin llegar a elaborar una contraargumentación hasta que, finalmente, se muestra dispuesto a aceptar algunas de las críticas que le están dirigidas. 
Creo que este diálogo es oportuno para concluir ya que revela dos cuestiones que me propuse resaltar desde el comienzo: la actualidad del debate ontológico, confirmado por un giro hacia y de la ontología, y la tensión que este giro mantiene con la metafísica. Lo que se juega en esta disputa interpretativa no es solamente el lugar de Marx en la historia del pensamiento occidental, sino también, y quizás en primer lugar, lo que Marx nos permite pensar más allá de sí mismo y de todo lo que en su discurso es deudor del esquematismo metafísico. De lo que se trata, tal como sugiere el título de un libro de Negri de 1979, es de leer y dar a leer a Marx más allá de Marx. De aferrarnos estrictamente a la letra de sus escritos ni siquiera estaríamos en condiciones de afirmar una ontología dado que allí esta no aparece más que insinuada. Pero tampoco es cuestión de hacer con ellos lo que a uno le venga en gana, irracional o arbitrariamente. El "paso más allá" no equivale simplemente a dejar atrás o a dejar de lado. Muy por el contrario, dicho paso exige un compromiso o una responsabilidad teórica con el texto, $y$, asimismo, una intervención o una operación activa, una transformación de lo que se lee por parte de quien lee. Sabemos sobradamente que ningún intérprete, por leal que se quiera o que se crea, lleva a cabo su cometido sin modificar en mayor o menor medida eso mismo que interpreta. Llegado el caso, lo importante es saber qué se modifica y en qué sentido.

Hablar de una ontología marxiana ya es una incisión en el texto de Marx, un modo entre otros de incidirlo, de afectarlo. Como se ha podido ver, semejante operación pudo realizarse según procedimientos y estilos muy diferentes, con mayor o menor apego a la axiomática y al método de Marx pero siempre, al menos en lo que respecta a los autores concernidos por este análisis, con "espíritu marxista". Por mi parte, y en lo que refiere a este pequeño inciso, no pretendo nada distinto. Si aquí se critica la preeminencia del trabajo sobre otras formas de acción social no es para denunciar la falsedad de lo que Negri y Hardt llaman con razón los "dos presupuestos de la ontología marxiana": que "el mundo está creado por el trabajo" y "que este trabajo será siempre explotado mientras exista el capitalismo". Sin lugar a duda, esta es una de las más grandes y duraderas enseñanzas de Marx. Nada de lo que se haga con él o contra él, incluso más allá de él, puede desconocer esta verdad elemental. Ahora bien, tampoco se puede desconocer que en la creación del mundo participan otras fuerzas además del trabajo y que estas no dependen ni se derivan de la fuerza productiva. Estas afirmaciones no son irreconciliables. En la actualidad, y en buena parte gracias a Marx, es perfectamente concebible una ontología de las relaciones sociales en su conjunto, tanto de las relaciones productivas, que en el orden capitalista son relaciones de explotación y dominación, como de las relaciones improductivas, aquellas que no producen nada en sentido estricto o que, como mínimo, no se explican exclusivamente en función de su ganancia o utilidad. Esto es, para usar todavía una distinción aristotélica muy presente en el discurso de Marx, una ontología de la poiesis y de la praxis, es decir, de la acción cuyo fin es producir o fabricar alguna cosa y de la acción que es un fin en sí mismo, sin que ninguna de ellas prevalezca sobre la otra ni opere como principio modelador de la acción social. Para empezar, esta ontología exige deconstruir la oposición individuo/sociedad y, 
al mismo tiempo, formular un concepto de relación que no sea reapropiable por ningún tipo de binarismo. Pero esto no es todo. Pues aun si se concibe una teoría de la relaciones, de las acciones y de los procesos sociales, siempre se corre el riesgo de privilegiar un sentido primero y determinante de lo social operando de este modo una reducción a lo Uno en detrimento de la multiplicidad de la que se parte. Por esta razón, esta ontología también exige una desjerarquización de las relaciones sociales $y$, consecuentemente, una apertura considerable en la comprensión de lo social, de ese nombre que en rigor de verdad todavía no sabemos lo que engloba ya que desconocemos sus límites. Así quedaría trazada, al menos en sus rasgos más generales y todavía de manera muy deficiente, una ontología social que desafía el discurso metafísico justamente allí donde a este se lo reconoce más poderoso. Lo que queda por pensar con relación a esta y a cualquier otra ontología concebida en tensión con la tradición metafísica es el lugar que allí habrá de ocupar lo que Marx, en 1845, continúa llamando "esencia humana". Pues ninguna propuesta ontológica contemporánea, por radical que sea en su formulación, irá demasiado lejos si entre los presupuestos que critica no incluye aquel que hace del hombre y de su humanidad el sujeto exclusivo del ser social y el punto de referencia de todo lo que es o de todo lo que existe.

\section{Bibliografía}

(2012) ALVARO, D., "Marx y la ontología de lo común", Nómadas. Revista crítica de ciencias sociales y jurídicas, 36, pp. 13-29.

(2004) ARISTÓTELES, Metafísica, trad. H. Zucchi, Buenos Aires, Sudamericana.

(2009) ARISTÓTELES, Categorías / Sobre la interpretación, introd., trad. y notas J. Mittelmann, Buenos Aires, Losada.

(2006) BALIBAR, É., La filosofía de Marx, trad. H. Pons, Buenos Aires, Nueva Visión.

(2012) BALIBAR, É., "From Philosophical Anthropology to Social Ontology and Back: What to Do with Marx's Sixth Thesis on Feuerbach?",Postmodern Culture, Volume 22, Number

http://muse.jhu.edu/journals/postmodern_culture/toc/pmc.22.3.html

(2014) BALIBAR, É., La philosophie de Marx, Paris, La Découverte.

(2014) BALIBAR, É. y MORFINO, V. (comps.), II transindividuale. Soggetti, relazioni, mutazioni, Milano, Mimesis.

(2010) CURCIO, A. y ÖZSELÇUK, C., "On the Common, Universality, and Communism: A Conversation between Étienne Balibar and Antonio Negri", Rethinking Marxism: A Journal of Economics, Culture \& Society, Volume 22, Issue 3, pp. 312-328.

(1978) GOULD, C., Marx's Social Ontology: Individuality and Community in Marx's Theory of Social Reality, Cambridge, Mass., MIT Press. 
(1983), GOULD, C., Ontología social de Marx. Individualidad y comunidad en la teoría marxista de la realidad social, trad. M. Caso, México D. F., FCE.

(1968) GRANEL, G., "L'ontologie marxiste de 1844 et la question de la 'coupure'". En AAVV, L'endurance de la pensée. Pour saluer Jean Beaufret, Paris, Plon, pp. 267-317.

(2002) HARDT, M. y NEGRI, A., Imperio, trad. A. Bixio, Buenos Aires, Paidós.

(2003) HARDT, M. y NEGRI, A., El trabajo de Dionisos, trad. R. Sánchez Cedillo, Madrid, Akal.

(2004) HARDT, M. Y NEGRI, A., "Huellas marxianas". En A. Negri et al., Guías: cinco lecciones en torno a Imperio, trad. R. Rius y P. Salvat, Buenos Aires, Paidós, 2004, pp. 193-217.

(2001) HEIDEGGER, M., Carta sobre el humanismo, trad. H. Cortés y A. Leyte, Madrid, Alianza.

(2004) INFRANCA, A. y VEDDA, M., "Introducción". En G. Lukács, Ontología del ser social: El trabajo, ed. al cuidado de A. Infranca y M. Vedda, Buenos Aires, Herramienta.

(1984) JAY, M., Marxism and Totality. The Adventures of a Concept from Lukács to Habermas, Berkley - Los Angeles, University of California Press.

(1996) LACHTERMAN, D., "The Ontology of Production in Marx: The Paradox of Labor and the Enigma of Praxis", Graduate Faculty Philosophy Journal, Vol. 19, 1, pp. 3-23.

(1984) LUKÁCS, G., "Die ontologischen Grundlagen". En F. Benseler (Hrsg.), Revolutionaeres Denken: Georg Lukács: eine Einführung in Leben und Werk, Darmstadt und Neuwied, Luchterhand, pp. 266-283.

(1984, 1986) LUKÁCS, G., ZurOntologie des gesellschaftlichen Seins, Werke, Bd. 13/14, Darmstadt und Neuwied, Luchterhand.

(2004) LUKÁCS, G., Ontología del ser social: El trabajo, ed. al cuidado de A. Infranca y M. Vedda, Buenos Aires, Herramienta.

(2007) LUKÁCS, G., Marx, ontología del ser social, ed. de M. Ballestero, Madrid, Akal.

(2013) LUKÁCS, G., Ontología del ser social: La alienación, ed. al cuidado de A. Infranca y M. Vedda, Buenos Aires, Herramienta.

(1969) MARX, K., "Thesenüber Feuerbach". En Marx-Engels Werke Bd. 3. Berlin/DDR, Dietz Verlag, pp. 533-535.

(1982) MARX, K., "Diferencia entre la filosofía democriteana y epicúrea de la naturaleza". En K. Marx, Escritos de juventud, trad. W. Roces, México, FCE, pp. 15-70.

(1985) MARX, K., "Tesis sobre Feuerbach". En K. Marx y F. Engels, La ideología alemana, trad. W. Roces, Buenos Aires, Ediciones Pueblos Unidos. 
(2011) MARX, K., Elementos fundamentales para la crítica de la economía política (Grundrisse) 1857-1858, vol. 2, trad. P. Scaron, México, Siglo XXI.

(2003) MURPHY, T., "The Ontological Turn in the Marxism of Georg Lukács and Antonio Negri", Strategies: Journal of Theory, Culture \& Politics, Volume 16, Issue 2, pp. 163-184.

(1993) NEGRI, A., La anomalía salvaje: ensayo sobre poder y potencia en Baruch Spinoza, trad. G. de Pablo, Barcelona, Anthropos.

(2004) NEGRI, A., "A propósito de la ontología social. Trabajo material, inmaterial y biopolítica". En A. Negri et al., Guías: cinco lecciones en torno a Imperio, trad. R. Rius y P. Salvat, Buenos Aires, Paidós, 2004, pp. 73-92.

(2009) SIMONDON, G., La individuación a la luz de las nociones de forma y de información, trad. P. Ires, Buenos Aires, Cactus / La Cebra.

(2011) TERTULIAN, Nicolas, "Préface". En G. Lukács, Ontologie de l'être social. Le travail. La production, Paris, Delga, pp. 5-49.

(2009) YU, W., "Marx'sontology of the praxis-relations of social production", Frontiers of Philosophy in China, Volume 4, Issue 3, pp. 400-416. 